\title{
Correction to: Language and imagined Gesellschaft: Émile Durkheim's civil-linguistic nationalism and the consequences of universal human ideals
}

\section{Mitsuhiro Tada ${ }^{1}$}

Published online: 20 June 2020

(C) Springer Nature B.V. 2020

\section{Correction to: Theory and Society https://doi.org/10.1007/s11186-020-09394-1}

The original article has been updated. Unfortunately due to mistakes during the editing of the article, the article was published with a lack of some reference information in the main text. These mistakes have now been corrected.

Publisher's note Springer Nature remains neutral with regard to jurisdictional claims in published maps and institutional affiliations.

\begin{abstract}
Mitsuhiro Tada is an associate professor in the Faculty of Humanities and Social Sciences at Kumamoto University, Japan. His research focuses on sociological theory, the history of sociology, and issues pertaining to nationalism. In his first book, titled The Temporal Construction of the Social World: Theory of Social Systems as Sociological Phenomenology (Harvest-sha 2013), which received the Young Investigator's Award from the Japan Association for the Study on the History of Sociology, Tada theoretically clarified social order as a spontaneous temporal order by applying a phenomenological time analysis to Niklas Luhmann's social systems theory. He is currently researching the relationship between sociological theory and language. Tada's published English articles include "Intentionality of Communication: Theory of Self-Referential Social Systems as Sociological Phenomenology" (Schutzian Research, 2010), "Edmund Husserl in Talcott Parsons: Analytical Realism and Phenomenology" (Human Studies, 2013), “Time as Sociology's Basic Concept: A Perspective from Alfred Schutz's Phenomenological Sociology and Niklas Luhmann's Social Systems Theory" (Time \& Society, [2018] 2019), and "Language, Ethnicity, and the Nation-State: On Max Weber's Conception of "Imagined Linguistic Community"' (Theory and Society, 2018).
\end{abstract}

The online version of the original article can be found at https://doi.org/10.1007/s11186-020-09394-1

Mitsuhiro Tada

tada.mitsuhiro@gmail.com

1 Faculty of Humanities and Social Sciences, Kumamoto University, 40-1, Kurokami

2-chome,Chuo-ku, Kumamoto 860-8555, Japan 